\title{
Understanding the Value of Volunteer Involvement
}

\author{
Bryan Terry, Assistant Professor \\ Amy Harder, Assistant Professor \\ Dale Pracht, Assistant Professor \\ University of Florida
}

Volunteers can be an important resource of many nonprofit organizations. The ability to meet the mission, goals and objectives of nonprofit organizations often depends upon the effectiveness of volunteer involvement in direct service delivery or indirect program support. Volunteer involvement utilizes financial and non-financial resources of an organization. Given the challenges associated with coordinating and managing volunteers, nonprofit organizations should evaluate volunteer program initiatives. Utilizing a net benefits framework, this study evaluated volunteer programs in 4-H to understand the value of direct and indirect volunteer involvement. Findings showed county 4- $H$ programs that utilized volunteers to provide direct service to clientele as-well-as volunteers in indirect program support roles had nearly 50\% higher total benefits compared to programs that only used direct service volunteers. Additionally, results indicated challenges associated with coordinating and managing volunteers did not increase for programs that involve both direct and indirect volunteers compared to those that only utilized direct service volunteers. Finally, this research provided evidence that net benefits accrued at a higher rate for nonprofits that utilize both direct and indirect service volunteers compared to those involving only direct service volunteers.

Keywords: nonprofit management, volunteer management, program evaluation, net benefits

\section{Introduction}

Nonprofit and public organizations often rely on volunteers to carry out their mission and objectives (McCurley \& Lynch, 2006). This often includes providing direct service to clientele, as-well-as indirect support to the organization (Hartenian, 2007). Examples of direct services to clientele include tutors, youth and adult mentors, coaches, and those individuals that provide information to clients by telephone or other electronic media (Burke \& Liljenstolpe, 1992; McCurley \& Lynch, 2006; McKee \& McKee, 2008). In addition, indirect service volunteers serve in coordination and management roles between organizational staff, other volunteers, and clientele. Indirect service volunteers are volunteers that coordinate and manage specific activities and events, master volunteers that teach other volunteers, and committee members that assist paid staff in planning, implementing, and evaluating the goals and objectives of nonprofit and governmental organizations (Culp, 1999).
Hartenian (2007) conducted a study to understand the relationships between nonprofit agencies that are dependent upon volunteers and those that are not. The study concluded that organizations were more dependent upon direct service volunteers than indirect service volunteers. As an organization's dependence on direct service volunteers increased, its dependence on indirect service volunteers decreased. Hartenian's findings indicate that organizations may value direct and indirect service volunteers differently. This suggests that the common method of estimating the value of volunteer labor using a standardized value does not tell the true story of the benefits derived by organizations from volunteers.

More research is needed to understand the benefits of using direct and indirect service volunteers. The use of volunteers carries its own cost, as volunteers must be generated, educated, mobilized, and sustained (Culp, Deppe, Castillo, \& Wells, 1998; Culp \& Kohlhagen, 2004), which requires organizational resources. Thus, it is important to understand the optimal balance 
of direct and indirect service volunteers in order to maximize the use of organizational resources.

\section{Theoretical/Conceptual Framework \& Review of Literature}

Organizational accountability is the timely and consequential pursuit of mission goals (Peters \& Pierre, 2003). It has been driven by the ability to quantify and measure earned rewards and the culturally determined method of assessing and recognizing performance (Peters $\&$ Pierre, 2003). Program evaluation has been defined as a systematic approach that utilizes social research procedures to investigate the effectiveness of a program intervention (Rossi, Freeman, \& Lipsey, 1999). Program evaluations have been conducted to improve programs, provide accountability, increase knowledge, and to develop political support (Rossi et al., 1999). The principle purpose has been to obtain evidence related to the effectiveness of programs provided to clientele by those stakeholders that have been interested in creating, continuing, or improving programs (Rossi et al., 1999).

Similarly, Hatry (1999) stated that program evaluations should not only measure outcomes achieved by clientele, but also whether or not the outcome was the result of the program intervention. Given that there are costs associated with managing, coordinating and training volunteers, nonprofits need to approach volunteer administration as they would any other program initiative. This includes understanding whether the volunteer program has contributed to the accomplishment of the established organizational goals and objectives and at what cost.

Organizations derive benefits when resources have been used successfully (Thompson \& Strickland, 2003). For nonprofits, benefits can accrue when the mission, goals, and objectives are being met. Volunteers have often been an essential resource for nonprofit organizations (Graff, 2006). Organizational benefits from volunteers have included: organizational cost savings (Allen, Chi, Devlin, Gall, Hatry, \& Masterman, 1989), ability to provide needed services by local societies that are not provided otherwise (Ollis, 2001), access to volunteers with specialized skills (Craven, 2006); increased public support (Brennan, 2007), and detailed attention to clientele and service quality (Terry \& Israel, 2004). Brudney and Kellough (2000) surveyed 189 personnel managers of state agencies and confirmed these benefits provided by volunteers.

In addition to the benefits accrued by deploying volunteer resources, organizations also face challenges when involving volunteers. Boyd (2003) observed "Volunteers cannot improve their communities alone. Volunteers need the direction of leaders who can focus their efforts toward solving specific problems" (pp. 47-48). Providing leadership means there are financial costs associated with the use of volunteers, such as employee salaries and benefits, as well as legal fees and direct financial support for volunteer initiatives. In addition, there are non-financial costs such as risk to clientele and damage to organizational reputation (Thompson \& Strickland, 2003). Some of these costs manifest themselves in terms of time. This includes time spent recruiting volunteers (Burke \& Liljenstolpe, 1992; McCurley \& Lynch, 2006; McKee \& McKee, 2008), providing orientation and training to volunteers (Vineyard, 1995), supervising volunteer involvement (Campbell \& Ellis, 1995; Little, 1999; Vineyard, 1996) evaluating volunteer and organizational performance (McCurley \& Lynch, 2006) and volunteer retention (Rusin, 1999). Increased time increases the economic cost to the organization. For other non-financial costs, such as poor service quality to clientele, there is a risk to clientele and damage to the organizational reputation. The larger the challenge the more cost to the organization. The key concept for organizations that utilize volunteers is the understanding that volunteers are not free.

This study was in part based on the work of Hager and Brudney (2005). Hager and Brudney stressed the importance of program evaluation and outcome measurement of programs designed to utilize volunteers. Their national study measured the net benefits of volunteer programs in over 2,000 public charities. Conceptually, net benefits reflect the difference between the benefits that volunteers contribute to an organization and the challenges associated with volunteer administration. Therefore, net benefits from volunteer involvement can serve as an indicator of performance within a volunteer program. Key to this discussion is the extent to 
which volunteers are involved within the organization and the value derived from that involvement. Understanding the value of volunteer involvement aids volunteer administrators in making decisions related to resource allocation. Although the study was not a measure of economic benefit, with additional research the results could be stated in economic terms. The power of the study was the ability to identify independently the benefits that volunteers provide and challenges associated with volunteer administration into single numeric measures. This gives a program manager the ability to benchmark, establish program baseline measurements, and develop continuous improvement strategies.

\section{Purpose \& Objectives}

The purpose of this research was to understand the value of volunteer involvement in a nonprofit youth development organization. Specifically, this study was conducted in the context of 4-H. 4-H programs are implemented on many levels - international, national, state, and county. For this article, the term " $4-\mathrm{H}$ program" refers holistically to the county $4-\mathrm{H}$ program. To understand the value of volunteer involvement, the following objectives were developed:

1. Describe the use of direct and indirect service volunteers in 4-H programs.

2. Determine if differences existed in the total benefits derived by $4-\mathrm{H}$ programs according to volunteer use.

3. Determine if differences existed in the total costs derived by $4-\mathrm{H}$ programs according to volunteer use.

4. Determine if differences existed in the total net benefits derived by $4-\mathrm{H}$ programs according to volunteer use.

\section{Methods}

A quantitative approach using survey methodology was utilized for this study. The target population for the study consisted of the volunteer administrators for $4-\mathrm{H}$ programs in Florida. For this study, volunteer administrators were defined as the individuals responsible for managing, coordinating, and training volunteers within the 4-H program. There were 62 volunteer administrators working in 67 counties in Florida. A census was taken of the population. The use of a census decreases the threat to validity caused by sampling error (Dillman, Smyth, \& Christian, 2009).

A modified survey instrument originally developed by Hager and Brudney (2005) was used to collect data. The researchers obtained permission to use the questionnaire prior to implementation. The questionnaire was organized into three sections. The first section contained six items that measured the organizational benefits of volunteer involvement based upon a three point scale $(1=$ not at all, $2=$ moderate extent, 3 = great extent $)$. These items accurately reflected the organizational benefits discussed earlier in this article. The researchers acknowledge that three response categories limit the variability of responses. Cronbach's alpha coefficient was used to calculate the reliability level of the internal scale ex post facto. A coefficient alpha of .92 existed, indicating a high degree of internal consistency among measurement items.

The second section contained nine items to measure the challenges associated with volunteer involvement based upon a three point scale $(1=$ not a problem, $2=$ small problem, $3=$ big problem). Challenges reflect increased time to perform a volunteer administration function, financial cost to support volunteer initiatives, or increased risk to organizational reputation. Each of these items was identified by other experts in the field and accurately reflects the challenges in volunteer administration. Coefficient alpha for the internal scale was .90 , indicating a high degree of internal consistency among measurement items.

The third section contained two items to identify the extent that volunteers provide indirect or direct service to the organization based upon a four point scale $(1=$ Not at all, $2=$ Seldom, 3 = Sometimes, $4=$ Often $)$. Indirect service to the program by volunteers included recruiting other volunteers, training other volunteers, managing and coordinating events and activities on behalf of the organization, and program planning. Direct service volunteers mentor and provide nonformal educational experiences to youth. In addition, county population data and advisory committee involvement was collected. 
Participants were sent an electronic invitation to complete the questionnaire with instructions on the purpose of the study, the study procedures, and how to access and respond to the questionnaire. Survey Monkey was utilized to collect the survey responses. The survey yielded a usable response rate of $90.32 \%$ $(N=56)$. Non-response bias was addressed following guidelines suggested by Lindner, Murphy, and Briers (2001). Given the high response rate and the lack of sufficient nonrespondents, respondents were grouped as early or late respondents. The two groups were compared on their responses using $t$-tests. No differences were found between the responses of early and late respondents so the results are generalizable to the target population.

Descriptive statistics were used for the first objective. Objectives 2 through 4 were analyzed first by calculating total benefits, total challenges, and net benefits. Consistent with Hager and Brudney (2005), the survey contained eight challenges items and only six benefits items; the response value of each benefit was multiplied by 1.33 so that the benefits would have as much weight as the challenges in the net benefits measure. The weighted response values assigned to the six benefits by a participant were summed to create a total benefits score for the participant's 4-H program. The range of values could be 0 , indicating the program had no benefit from volunteer involvement, to +16 , indicating high benefit related to volunteer involvement. Similarly, the total challenges score for a participant's 4-H program was calculated by summing the response values assigned to the eight challenges by the participant. The range of values could be 0 , indicating the program had no challenges from volunteer involvement, to -16 , indicating high challenges related to volunteer involvement.

Net benefits refer to the difference between the benefits that volunteers provide to the organization and the challenges of managing, coordinating and training volunteers. Net benefits were calculated by subtracting the total challenges from the total benefits for each $4-\mathrm{H}$ program. The range of net benefits could be +16 , indicating the program generated all benefits with no challenges associated with volunteers, to -16 , indicating the organization generated no benefits and all challenges from volunteer involvement.

To complete the analysis of objectives two through four, Analysis of Variance (ANOVA) was performed using SPSS 15.0 to determine if a statistical difference existed between county programs based upon the extent that the 4-H programs used indirect service volunteers. Four comparison groups were created and analyzed. Group 1 included volunteer programs that used indirect service volunteers often, Group 2 included volunteer programs that used indirect service volunteers sometimes, Group 3 included volunteer programs that used indirect service volunteers seldom, and Group 4 included volunteer programs that only used direct service volunteers. Tukey's post hoc procedure was used to examine differences in the mean net benefits between all pairs based upon the level of indirect volunteer utilization and the effect size was reported using Eta squared.

\section{Results}

\section{Volunteer Use}

In comparing volunteer involvement, respondents indicated they sometimes $(M=$ 2.82, $S D=0.47)$ used volunteers for direct service to youth. Similarly, they sometimes $(M=$ $1.50, S D=0.83$ ) used volunteers for indirect program support. However, as shown in Table 1, respondents were more likely to report they often used volunteers for direct service to youth $(85.71 \%)$ versus for indirect program support $(11.11 \%)$.

Table 1

Use of Direct and Indirect Service Volunteers by Respondents

\begin{tabular}{lcccc}
\hline & Not at all & Seldom & Sometimes & Often \\
Type of Volunteer & $f(\%)$ & $f(\%)$ & $f(\%)$ & $f(\%)$ \\
\hline Direct service to youth & 0.00 & 3.57 & 10.71 & 85.71 \\
Indirect program support & 9.26 & 40.74 & 38.89 & 11.11 \\
\hline
\end{tabular}

Note. $N=56$ 
Total Benefits of Volunteer Involvement

The total benefits of a $4-\mathrm{H}$ program varied by the use of indirect volunteers, $F(3,52)=$ $4.93, p<.01$. The range of values of total benefits could be 0 (no benefit) to +16 (high benefit). Use of middle management volunteers accounted for $22.10 \%$ of the variance in the dependent variable. Tukey's post hoc procedure indicated that 4-H programs that utilized indirect service volunteers "often," Group 1, $(M=14.63$, $S D=2.06)$ and 4-H programs that utilized indirect service volunteers "sometimes," Group 2, $(M=13.54, S D=1.86)$ had significantly higher total benefits compared to 4-H programs that did not use indirect volunteers, Group 4, $(M$ $=9.97, S D=3.92$ ). There was not a significant difference in total benefits between any other comparison groups (see Table 2).

Table 2

Differences in Total Benefits According to Volunteer Use $(n=56)$

\begin{tabular}{|c|c|c|c|c|c|}
\hline & $d f$ & $M S$ & \multicolumn{2}{|c|}{$F$} & $p$ \\
\hline \multirow{2}{*}{$\begin{array}{l}\text { Between Groups } \\
\text { Within Groups }\end{array}$} & 3 & 29.19 & $4.93 *$ & & \multirow[t]{2}{*}{.00} \\
\hline & 52 & 5.92 & & & \\
\hline \multirow[t]{2}{*}{ (I) Indirect Service Utilization } & \multirow{2}{*}{\multicolumn{2}{|c|}{$\begin{array}{c}\text { (J) Indirect Service } \\
\text { Utilization }\end{array}$}} & Mean & Standard & \\
\hline & & & Difference & Error & $p$ \\
\hline \multirow[t]{3}{*}{ Group 1} & Grou & & 1.09 & 1.12 & .77 \\
\hline & Groul & & 2.42 & 1.12 & .15 \\
\hline & Grou & & $4.66^{*}$ & 1.41 & .01 \\
\hline \multirow[t]{3}{*}{ Group 2} & Groul & & -1.09 & 1.12 & .76 \\
\hline & Groul & & 1.33 & 0.73 & .28 \\
\hline & Groul & & $3.57 *$ & 1.12 & .01 \\
\hline \multirow[t]{3}{*}{ Group 3} & Groul & & -2.42 & 1.12 & .15 \\
\hline & Groul & & -1.33 & 0.73 & .28 \\
\hline & Groul & & 2.24 & 1.12 & .20 \\
\hline \multirow[t]{3}{*}{ Group 4} & Groul & & $-4.66^{*}$ & 1.41 & .01 \\
\hline & Groul & & $-3.57 *$ & 1.12 & .01 \\
\hline & Grou & & -2.24 & 1.12 & .20 \\
\hline
\end{tabular}

Note. ${ }^{*} p<.05, * * p<.01$.

Group 1 - Volunteer Programs that utilize indirect volunteers often and direct service volunteers.

Group 2 - Volunteer Programs that utilize indirect volunteers sometimes and direct service volunteers.

Group 3 - Volunteer Programs that utilize indirect volunteers seldom and direct service volunteers.

Group 4 - Volunteer Programs that utilize only direct service volunteers.

\section{Total Challenges of Volunteer Involvement}

An ANOVA procedure showed total costs in $4-\mathrm{H}$ programs that used only direct service volunteers compared to volunteer programs that used direct service and indirect service volunteers did not vary $F(2,52)=2.07, p>.05$ (see Table 3). The range of values for total costs could be 0 (no challenges) to 16 (high challenges).

Table 3

Differences in Total Challenges According to Volunteer Use $(n=56)$

\begin{tabular}{lcccc}
\hline & $d f$ & $M S$ & $F$ & $p$ \\
\hline Between Groups & 3 & 10.19 & 2.07 & .12 \\
Within Groups & 52 & 4.93 & & \\
Total & 55 & & & \\
\hline
\end{tabular}


Net Benefits of Direct and Indirect Volunteers

The net benefits of a volunteer program varied by the use of direct and indirect volunteers, $F(3,52)=6.36, p<.01$ (see Table $4)$. The range of values of net benefits could be 16 (all challenges and no benefit) and +16 (all benefits and no challenges). Use of middle management volunteers accounted for $26.80 \%$ of the variance in the dependent variable. Tukey's post hoc procedure indicated that $4-\mathrm{H}$ programs that used indirect service volunteers "often," Group 1, $(M=6.80, S D=2.70)$ and
4-H programs that used indirect service volunteers "sometimes," Group 2, $(M=5.04, S D$ $=3.10)$ had statistically significant higher net benefits compared to 4-H programs that only used direct service volunteers, Group 4, $(M=-$ $0.19, S D=3.96$ ). Additionally, Group $14-\mathrm{H}$ programs $(M=6.80, S D=2.70)$ had statistically significant higher net benefits compared to $4-\mathrm{H}$ programs that used indirect service volunteers "seldom," Group 3, $(M=2.58, S D=3.59)$. There was not a significant difference in net benefits between any other comparison groups.

Table 4

Differences in Net Benefits According to Volunteer Use $(N=56)$

\begin{tabular}{lrrrl}
\hline & $d f$ & $M S$ & $F$ & $p$ \\
\hline Between Groups & 3 & 71.95 & $6.36^{*}$ & .01 \\
Within Groups & 52 & 11.31 & & \\
Total & 56 & & &
\end{tabular}

\begin{tabular}{ccccc} 
(I) Indirect Service Utilization & (J) Indirect Service & Mean & Standard & \\
& Utilization & Difference & Error & $p$ \\
\hline Group 1 & Group 2 & 1.75 & 1.55 & .67 \\
& Group 3 & $4.22^{*}$ & 1.55 & .04 \\
& Group 4 & $6.99^{*}$ & 1.94 & .00 \\
Group 2 & Group 1 & -1.75 & 1.55 & .67 \\
& Group 3 & 2.47 & 1.01 & .08 \\
& Group 4 & $5.23^{*}$ & 1.55 & .01 \\
Group 3 & Group 1 & $-4.22^{*}$ & 1.55 & .04 \\
& Group 2 & -2.47 & 1.01 & .08 \\
& Group 4 & 2.77 & 1.55 & .29 \\
& Group 1 & $-6.99 * *$ & 1.94 & .00 \\
& Group 2 & $-5.23 *$ & 1.55 & .01 \\
& Group 3 & -2.77 & 1.55 & .29 \\
\hline
\end{tabular}

Note. $* p<.05, * * p<.01$.

Group 1 - Volunteer Programs that utilize indirect volunteers often and direct service volunteers.

Group 2 - Volunteer Programs that utilize indirect volunteers sometimes and direct service volunteers.

Group 3 - Volunteer Programs that utilize indirect volunteers seldom and direct service volunteers.

Group 4 - Volunteer Programs that utilize only direct service volunteers.

\section{Conclusions}

There were four objectives related to $4-\mathrm{H}$ programs' use of direct and indirect service volunteers that were tested by this study. All 4-H programs in Florida $(73 \%)$ provide opportunities for volunteers to provide nonformal educational opportunities (direct service) to youth. Fifty percent of 4-H programs involve volunteers in indirect program support roles. At the same time, it is much more likely that $4-\mathrm{H}$ programs will not provide indirect service opportunities for volunteers compared to direct service roles.

The results for the second objective showed that $4-\mathrm{H}$ programs that use both direct and indirect volunteers have higher total benefits. Objective three was not supported, providing no evidence that using only direct service volunteers results in fewer challenges associated with volunteer involvement compared to $4-\mathrm{H}$ programs that use both direct and indirect service volunteers. The results partially support objective four that $4-\mathrm{H}$ programs that use both 
direct and indirect volunteers will have higher net benefits. Consistent with Hager and Brudney (2005), volunteer programs realized higher total benefits and higher net benefits when volunteers were used in both direct and indirect roles. Interestingly, 4-H volunteer programs in this study had higher total challenges compared to the other study, but unlike the Hager and Brudney study, these total challenges did not increase when the level of volunteer involvement increased.

By replicating the framework by Hager and Brudney (2005), study results provided insightful information. First, Florida 4-H achieved an overall net benefit from the nearly 15,000 adult and youth volunteers. At the same time, the net benefits of $4-\mathrm{H}$ volunteers in Florida $(M=3.70, S D=3.82)$ were considerably lower compared to the other study $(M=8.67$, $S D=$ not reported). Closer examination showed that $21 \%$ of volunteer programs in $4-\mathrm{H}$ had negative net benefits; this compares to $8 \%$ of the volunteer programs in the Hager and Brudney study. Each study had about $40 \%$ of volunteer programs with net benefits between 5.00 and 10.00; however the Hager and Brudney study had $24 \%$ of volunteer programs with net benefits that ranged from 10 to 16 , whereas this study found only one volunteer program $(1.78 \%)$ in this range. Further examination showed that the challenges associated with recruiting sufficient volunteers, recruiting volunteers with appropriate skills and expertise, and lack of paid staff time to train and supervise volunteers were significantly higher in this study compared to the previous study and contributed to lower net benefits.

\section{Implications}

The study contributes to research and practice that is concerned with nonprofit organizations that rely upon volunteers to accomplish their mission and objectives. The national research agenda for Agricultural Education and Communication identified the need to engage citizens in community action through leadership education and development (Osborne, 2007). Theoretically, the ability of an organization to engage citizens to accomplish it goals and objectives depends upon the effectiveness of an organization to coordinate, manage, and lead volunteers (Boyce, 1971; Culp et al., 1998; McCurley \& Lynch, 2006; Penrod, 1991). The authors agree with Hartenian (2007) that "agencies, must provide for volunteer ownership of ideas and programs to enhance their commitment to the agency" (p. 332); however as this study showed, this is much more related to expanding opportunities for volunteers rather than organizational dependency.

In Florida, 4-H programs that involve both direct service and indirect service volunteers generated nearly $50 \%$ more total benefits compared to programs that involve only direct service volunteers. These findings have implications for administrators that are directly and indirectly responsible for volunteer involvement. Thompson and Strickland (2003) noted that organizations, including nonprofits, accrue benefits when resources have been deployed successfully. This includes organizational cost savings (Allen et al., 1989), ability to provide needed services by local societies that are not provided otherwise (Ollis, 2001), access to volunteers with specialized skills (Craven, 2006); increased public support (Brennan, 2007), and detailed attention to clientele and service quality (Terry \& Israel, 2004). This study provides a better understanding of the extent of these benefits service volunteers. Other organizations with similarly organized volunteer programs may experience the same increase in benefits.

At the same time, volunteer involvement comes at a cost. This includes both financial and non-financial costs. This study showed that these costs were higher in Florida 4-H, but does not increase by expanding volunteer involvement into indirect program support roles. Volunteer recruitment was a significant challenge identified in this study. Not only was there an inability to recruit sufficient volunteers, but also the inability to recruit volunteers for specific roles. These factors drive down net benefits in Florida 4-H and will drive down net benefits in other volunteer programs as well. The net benefits framework used in this study provided the ability to identify these challenges and provides an opportunity to address these challenges through focused training.

One of the most important aspects of this study for volunteer administrators and nonprofit leaders relates to measuring the value of volunteer programs. Nonprofits must continuously justify expenditures for initiatives; 
this includes volunteer program expenditures. Using the net benefits framework, 4-H programs in Florida were able to measure and communicate the benefits, challenges and net benefits of volunteer programs using a standard. Having this standard allowed 4-H to establish a benchmark the volunteer program and then gauge future progress. This capability would also benefit other Extension programs that involve volunteers as well as other programs such as FFA.

However, the study is not without limitations. Although the survey instrument was easy to use and implement, having only three response choices reduced the variability of the results. A modified instrument with more response categories could improve a volunteer program administrator's ability to identify critical need areas. Even with its limitations, using the instrument developed by Hager and Brudney (2005) provided the ability to benchmark volunteer programs and identify critical program need areas. Another limiting factor of the study was method bias. The study relied on the perceptions of the program administrator responsible for managing and coordinating volunteers. This fact may lead to results that do not reflect reality in a given program. To reduce bias errors, participants were given instructions prior to the assessment.

\section{Recommendations}

This study provides several opportunities for future research. The model and assessment method should be replicated by additional organizations, such as other state $4-\mathrm{H}$ programs and FFA. This would provide additional information that could lead to improvement of future studies. A study to assess the desirable competencies of volunteer administrators would be very useful. A better understanding of these competencies would provide more insight into the aspects that increase the benefits and reduce the challenges of volunteer involvement. Finally, an external assessment utilizing the same net benefits assessment could be undertaken and the results could then be compared to this study. This would add validity and value to the research and serve as support for future training initiatives.

To increase the benefits of volunteer involvement, volunteer administrators are encouraged to set the tone for volunteer involvement by reviewing the organizational mission and objectives and identifying how volunteers contribute to its accomplishment. Additionally, volunteer administrators should identify unmet organizational initiatives, paying close attention to unmet support roles that would improve service delivery to clientele, enhance volunteer satisfaction, reduce costs, or save time. Volunteer roles should be developed for any unmet needs and recruitment strategies used to match the interests, skills and abilities of a volunteer with a volunteer role that meets an unmet need. Support needs to be provided to volunteers through training and recognition. Finally, volunteer administrators should continuously assess the volunteer program for areas of improvement.

To reduce the challenges associated with volunteer involvement, nonprofit and volunteer administrators need to gain an understanding of drivers of volunteer cost and then measure their impact on net benefits. Challenges that are identified should be reduced through policy change, professional development training, or increasing the capacity of volunteers. In this study program administrators were able to identify the drivers of the volunteer challenges and have developed training for volunteer administrators and volunteers.

The study provides practical guidance to volunteer administrators that seek to increase the value to their organization from volunteers. This includes the need: (a) to evaluate volunteer programs for continuous improvement; (b) to focus on the challenges that decrease organizational value; and (c) to focus on expanding volunteer involvement and not volunteer dependence. Volunteer administrators can determine the net benefits in their own organizations using this study's methodology and use those results to focus specific in-service training strategies. This type of feedback would help other practitioners as well. 


\section{References}

Allen, J., Chi, K., Devlin, K., Fall, M., Hatry, H., \& Masterman, W. (1989). The private sector in state service delivery: Examples of innovative practices. Washington, D.C.: Urban Institute Press.

Boyce, M. (1971). A systematic approach to leadership development. Washington, D.C.: USDA, Extension Service.

Boyd, B. L. (2003). Identifying competencies for volunteer administrators for the coming decade: A Delphi study. Journal of Agricultural Education, 44(4), 47-56. doi: 10.5032/jae.2003.04047

Brennan, M. (2007). Placing volunteers at the center of community development. International Journal of Volunteer Administration, 24(4), 5-13.

Brudney, J. L., \& Kellough, E. (2000). Volunteers in state government: Involvement, management and benefits. Nonprofit and Volunteer Sector Quarterly, 29, 111-130.

Burke, M. A., \& Liljenstolpe, C. (1992). Recruiting volunteers: A guide for nonprofits. Boston, MA: Thomson.

Campbell, K. N., \& Ellis, S. J. (1995). The help I don't have enough time guide to volunteer management. Philadelphia, PA: Energize, Inc.

Craven, J. (2006). Involving international online volunteers: Factors for success, organizational benefits, and new views of community. International Journal of Volunteer Administration, 24(1), 15-23.

Culp, K., III. (1999). Types of volunteers. Columbus, OH: Ohio State University Extension.

Culp, K., III, Deppe, C. A., Castillo, J. X., \& Wells, B. J. (1998). The GEMS model of volunteer leadership administration. Journal of Volunteer Administration, 16(4), 36-41.

Culp, K., III, \& Kohlhagen, B. S. (2004). Kentucky 4-H agents' perceptions of their levels of competency and frequency of use of volunteer administration function. Journal of Agricultural Education, 45(2), 1-13. doi: 10.5032/jae.2004.02001

Graff, L. L. (2006). Declining profit margin: When volunteers cost more than they return. International Journal of Volunteer Administration, 24(1), 24-32.

Dillman, D., Smyth, J. D., \& Christian, L. M. (2009). Internet, mail, and mixed-mode surveys (3rd ed.). Hoboken, NJ: John Wiley \& Sons, Inc.

Hager, M. A., \& Brudney, J. L. (2005). Net benefits: Weighing the challenges and benefits of volunteers. The Journal of Volunteer Administration, 21(1), 26-31.

Hartenian, L. S. (2007). Nonprofit agency dependence on direct service and indirect support volunteers: An empirical investigation. Nonprofit Management and Leadership, 17(3).

Hatry, H. P. (1999). Performance measurement: Getting results. Washington, D.C.: The Urban Institute Press. 
Lindner, J. R., Murphy, T. H. \& Briers, G. E. (2001). Handling Non-response in Social Science Research. Journal of Agricultural Education, 42(4), 43-53. doi: 10.5032/jae.2001.04043

Little, H. (1999). Volunteers: How to get them, how to keep them. Naperville, IL: Panacea Press, Inc.

McCurley, S., \& Lynch, R. (2006). Volunteer management: Mobilizing all the resources of the community (2nd ed.). Kemptville, ON: Johnstone Training and Consultation, Inc.

McKee, J., \& McKee, T. W. (2008). The new breed: Understanding and equipping the 21st century volunteer. Loveland, CO: Group.

Ollis, T. (2001). Volunteers, ideology and practice, towards a new century of volunteerism. Ethos, 9(2), $11-17$.

Osborne, E. W. (Ed.). (2007, May). National research agenda for agricultural education and communication: 2007-2010. Published by the American Association for Agricultural Education.

Penrod, K. M. (1991). Leadership involving volunteers: The L-O-O-P model. Journal of Extension, 29, $9-11$.

Peters, B. G., \& Pierre, J. (2003). Handbook of public administration. Thousand Oaks, CA: Sage.

Rossi, P. H., Freeman, H. E. \& Lipsey, M. W. (1999). Evaluation: A systematic approach (6th ed.). Thousand Oaks, CA: Sage Publications.

Rusin, J. B. (1999). Volunteers wanted: A practical guide to finding and keeping good volunteers. Mobile, AL: Magnolia Mansion Press.

Terry, B. D., \& Israel, G. D. (2004). Agent performance and customer satisfaction. Journal of Extension, 42(6). Retrieved from http://www.joe.org/joe/2004december/a4.php

Thompson, A. A., Jr., \& Strickland, A. J. (2003). Strategic management: Concepts and cases (13th ed.). New York, NY: McGraw-Hill.

Vineyard, S. (1995). The great trainer's guide. Downers Grove, IL: Heritage Arts Publishing.

Vineyard, S. (1996). Stop managing volunteers: New competencies for volunteer administrators. Downers Grove, IL: Heritage Arts Publishing.

BRYAN D. TERRY is an Assistant Professor in the Department of Family, Youth and Community Sciences at the University of Florida, PO Box 110310, Gainesville, FL 32611-0310. terrys1@ufl.edu

AMY HARDER is an Assistant Professor in the Department of Agricultural Education and Communication at the University of Florida, PO Box 110540, Gainesville, FL 32611-0540. amharder@ufl.edu

DALE W. PRACHT is an Assistant Professor in the Department of Family, Youth and Community Sciences at the University of Florida, PO Box 110310, Gainesville, FL 32611-0310. dpracht@ufl.edu 